Fecha de recepción: febrero 2019 Fecha de aceptación: julio 2019 Versión final: noviembre 2020

\section{Inovação social e divulgação da ciência: o design apresenta a astronomia para crianças}

Anderson Antonio Horta ${ }^{1}$, Clara Santana Lins Cerqueira ${ }^{2}$, Délcio Julião Emar de Almeida ${ }^{3}$, Michelle Alvarenga Pinto Cotrim $^{4}$ e Rita Aparecida da Conceição Ribeiro ${ }^{5}$

Resumo: $\mathrm{O}$ artigo apresenta a perspectiva da utilização das ferramentas do Design para a divulgação científica para crianças a partir do projeto "Animando o Ano da luz: o design apresenta a astronomia para crianças", desenvolvido pelo Grupo de Pesquisa Design e Representações Sociais da Universidade do Estado de Minas Gerais e financiado pela Fundação de Amparo à Pesquisa do Estado de Minas Gerais (FAPEMIG). Sua proposta é aliar o conhecimento específico acerca da Astronomia aos processos de construção simbólica do Design adaptando-os à linguagens e comunicações que permitam apresentar um universo do conhecimento da ciência de forma lúdica. A metodologia empregada buscou promover a interface entre os processos de ensino e aprendizagem, com o caráter lúdico dos dispositivos criados pelo design. Os processos metodológicos incluem levantamento de referencial bibliográfico, estudo das necessidades comunicacionais e projetação do material. O presente artigo abordará a primeira fase do projeto, contemplando a projetação, divulgação e distribuição do kit de paper toys com personagens que representam o Sistema Solar em dois eventos no ano de 2017, na cidade de Belo Horizonte, Brasil.

Palavras chave: design - divulgação científica - ensino - astronomia.

[Resumos em espanhol e inglês nas páginas 63-64]

(1) Designer, pesquisador e professor do curso de Design no Centro Universitário de Belo Horizonte, Brasil.

(2) Designer, mestra pelo Programa de Pós-Graduação em Design da Universidade do Estado de Minas Gerais-UEMG, Brasil.

(3) Designer, pesquisador e professor no Centro Universitário de Belo Horizonte na Faculdade Promove de Sete Lagoas.

(4) Designer e discente no Programa de Doutorado em Design da Universidade do Estado de Minas Gerais.

${ }^{(5)}$ Investigadora y Docente del Programa de Post-Graduación en Diseño de Universidade do Estado de Minas Gerais-UEMG, Brasil. Líder do Grupo de Pesquisa Design e Representações Sociais. Investigadora da FAPEMIG. 


\section{Introdução}

O ensino da astronomia para crianças apresenta-se como um desafio, principalmente devido ao desconhecimento e à confusão entre as informações que são apreendidas. Como forma de tornar o ensino desse conteúdo claro e atrativo para as novas gerações, é fundamental promover estratégias que fujam das armadilhas dos saberes do senso comum. Nesse sentido, o Design pode ser entendido como uma ferramenta que contribui de forma significativa no processo de aprendizagem, ao utilizar recursos que permitem a construção de caminhos para uma compreensão do conhecimento a partir de linguagens metafóricas. Somado a isso, perpassa os diversos processos sociais e sua característica multidisciplinar possibilita as mais diversas interações com os variados campos do conhecimento. Nesse contexto, foi proposto o projeto "Animando o ano da luz: o design apresenta a astronomia para crianças", visando a interface do design com a educação, financiado pela Fundação de Amparo à Pesquisa do Estado de Minas Gerais - FAPEMIG.

O projeto tem como objetivo a difusão do conhecimento científico para crianças e adolescentes, através da apresentação de fundamentos da astronomia, tendo como foco principal o sistema solar. A demanda surgiu como fruto de uma parceria anterior (2013-2016) entre o grupo de pesquisa Design e Representações Sociais do Programa de Pós-Graduação em Design da Universidade do Estado de Minas Gerais - PPGD/UEMG e o Grupo de Astronomia UFMG/Icex/Física, responsável pela administração do Observatório Astronômico Frei Rosário (OAFRO) -localizado na Serra da Piedade, Minas Gerais, Brasil.

O projeto foi dividido em dois momentos. A primeira parte, já finalizada, contemplou o desenvolvimento de um kit em papel, contendo dez personagens no formato de paper toys planificados que apresentam o Sol, os planetas do Sistema Solar (Mercúrio, Vênus, Marte, Terra, Júpiter, Saturno, Urano e Netuno) e a Lua, atribuindo a eles personalidades únicas e bem-humoradas. Os paper toys buscam trabalhar conceitos de astronomia, contribuir para o desenvolvimento do controle motor fino, e permitir que cada indivíduo acompanhe a atividade em seu próprio tempo, visando estimular o processo de aprendizagem de forma lúdica e prazerosa. Já a segunda parte, ainda em andamento, propõe a realização de drops (filmes de curta-metragem) para publicação na internet. Dessa forma, o projeto busca aliar o conhecimento específico acerca da Astronomia aos processos de construção simbólica do Design adaptando-os à linguagens e comunicações que permitam apresentar um universo do conhecimento da ciência de forma lúdica.

A metodologia empregada buscou promover a interface entre os processos de ensino e aprendizagem, com o caráter lúdico dos dispositivos criados pelo design. Os processos metodológicos incluem levantamento de referencial bibliográfico, estudo das necessidades comunicacionais e projetação do material.

O presente artigo abordará a primeira fase do projeto, "Animando o ano da luz: o design apresenta a astronomia para crianças", contemplando a divulgação e distribuição do kit na feira Inova Minas FAPEMIG (15,16 e 17 de setembro de 2017, Belo Horizonte - MG) e como desdobramento desta participação, o convite e presença na iniciativa Laboratório+Aberto (organizada pelo Senai FIEMG em outubro, 2017, Belo Horizonte - MG). 


\section{O desafio da divulgação científica}

Física, química, matemática, ciências biológicas e astronomia. Qual seria o porquê de saber essas coisas? Qual a importância que esse conhecimento fará na vida das pessoas? Qual a diferença que tais informações trarão no dia-a-dia da grande massa da população? Inicia-se esse artigo apontando tais inquietações, no momento em que o mundo se encontra cada vez mais globalizado e universalizado, processos potencializados pelas novas tecnologias da informação, redes de comunicação e sistemas de compartilhamento e produção de informação cada vez mais eficientes e disseminados. Por outro lado, observa-se o crescimento da violência, agora não mais local, exatamente pelas características proporcionadas pela universalização de valores e, ao mesmo tempo, dos preconceitos, misoginia, racismo. A exploração desenfreada dos recursos naturais e radicalização de governos baseadas em atitudes ultranacionalistas colocam o planeta em rota perigosa de autodestruição. Entretanto, parafraseando Pachauri (2015), que afirma da impossibilidade de um plano B já que não existe um planeta $B$.

Tais apontamentos nos levam às questões iniciais desse artigo, que se referem à importância da divulgação e democratização de conhecimentos científicos para um público leigo. Afirma-se, portanto, que se fazem extremamente importantes e urgente tais reflexões, no sentido de propor uma discussão ampliada desses conteúdos, normalmente restritos a públicos especializados. Segundo Morin (2006), o conhecimento científico possui a função de dissipar a complexidade dos fenômenos, revelando as ordens simples a que estão associados. Entretanto, o autor argumenta que tais fenômenos são, por vezes, mais mutilados do que elucidados, produzindo cegueira e simplificações (Morin, 2006). Entretanto, não se deve confundir a questão das simplificações com a falta de complexidade, mas antes propor "um pensamento capaz de lidar com o real, de com ele dialogar e negociar" (Morin, 2006, p. 6).

Portanto, discutir a respeito da divulgação e democratização de conteúdos de ordem científica é imprescindível para a compreensão do mundo complexo no qual todo indivíduo encontra-se inserido. Morin (2006, p. 10) argumenta, outrossim, que na maioria das vezes, os indivíduos e sociedades se encontram submetidos a princípios reguladores que operam no sentido de separar, unir, hierarquizar e centralizar conhecimentos, princípios esses “'supralógicos' de organização do pensamento ou paradigmas, princípios ocultos que governam nossa visão das coisas e do mundo sem que tenhamos consciência disso". Vive-se em um mundo em que as relações e dinâmicas sociais interferem na visão de mundo dos sujeitos sociais e esses mesmos sujeitos, a partir de suas percepções, retroalimentam e transformam formas de se perceber e (re)codificar o mundo culturalmente construído. Esse mundo de cultura é volátil e se encontra em constante transformação, resultado do esforço coletivo de seus atores, tanto aqueles que concebem ideias e valores, quanto aqueles que as disseminam quanto os que as consomem (McCraken, 2007).

Portanto, não seria temerário afirmar que, na dinâmica de intercâmbios culturais, desde produtos à sistemas de informação, faz-se necessária a consciência intencional dessas dinâmicas, já que a sociedade moderna não consome apenas produtos, mas antes significados e valores. McCraken (2007, p. 100) argumenta que os bens de consumo e consumidores são pontos de transferência, "estações na via do significado", atentando para o 
fato que, quando se fala de bens de consumo, não nos referimos apenas a bens materiais, mas antes ideias, valores e conhecimentos. $\mathrm{O}$ autor reconhece a existência de "um sistema grande e forte no cerne da sociedade de consumo moderna, que confere a essa sociedade parte de sua coerência e flexibilidade enquanto age como fonte constante de incoerência e descontinuidade" (McCraken, 2007, p. 100).

A opção ou não por produtos sustentáveis, a redução da utilização de combustíveis fósseis, modos de vida menos consumistas dentre outros pontos que caracterizam a sociedade contemporânea, ocorrem dentro dessa dinâmica de intercâmbios e interinfluências, submetidos que estão ao nível e qualidade do acesso a informações, compartilhadas e organizadas pelas instituições que possuem tal capital científico e simbólico para exercê-lo (Bourdieu, 2004). Todas essas decisões se baseiam em "realidades objetivas", produto da construção coletiva de quem possui maior capital, se manifestam por meio de representações, construções sociais que "se pretendem fundadas numa realidade dotado de todos os meios de impor seu veredito mediante o arsenal de métodos, instrumentos e técnicas de experimentar coletivamente acumulados e coletivamente empregados", afirma Bourdieu (2004, p. 34). Nesta mesma linha, McCraken (2007) sugere que os bens de consumo se moldam a partir da ordem da cultura, nos quais os princípios e categorias culturais ganham substância.

No que acreditar, portanto? Em que confiar ou filtrar, nesse imenso vórtice de representações que são difundidos pelos sistemas midiáticos, instituições e centros de poder? Não há como afirmar, mas é possível questionar se grande parcela da sociedade está conscientemente instruída para tais escolhas, detentora de informações transformadas em conhecimentos significativos. Kosminsky (2015) sugere que grande parte do conhecimento científico ainda permanece restrito à uma parcela reduzida da sociedade, em particular aos próprios pesquisadores, e quando esse conhecimento é divulgado, não vem acompanhado por noções científicas básicas que corroborem para a assimilação de conceitos mais complexos por parte do público não iniciado. Morin alerta que:

[...] os poderes criados pela atividade científica escapam totalmente aos próprios cientistas. Esse poder, em migalhas no nível da investigação, encontra-se reconcentrado no nível dos poderes econômicos e políticos. De certo modo, os cientistas produzem um poder sobre o qual não têm poder, mas que enfatiza instâncias já todo-poderosas, capazes de utilizar completamente as possibilidades de manipulação e de destruição provenientes do próprio desenvolvimento da ciência (Morin, 2005, p. 18).

Observa-se, dessa forma, que esses novos conhecimentos, gerados no âmago da restrita comunidade científica, levam à necessidade de uma reflexão a respeito da ética e desdobramentos igualmente éticos que eles evocam. Dessa forma, acredita-se que a ciência deve ser espaço aberto de discussão, passível de divulgação e acesso facilitados, no momento em que é ponto imprescindível para a construção da cidadania e participação política. Portanto, as estratégias que proporcionam esse acesso a informações relacionadas à ciência se encontram no âmago do tema tratado neste artigo. 


\section{O Design como processo social e as estratégias de divulgação da ciência}

Seria redundante aqui, estabelecer a nomenclatura design social, pois argumenta-se que toda ação do Design se faz uma ação social, no momento em que todo projeto de Design se direciona à sociedade, intencionando seu bem-estar, seu bem-viver. É indiscutível a importância do Design nos processos sociais, pois como afirma Lima \& Martins (2011, p. 117), o design se apresenta como manifestação em situações sociais, econômicas e políticas, já que está “[...] muito mais embasado numa relação com a sociedade do que somente apresentado como uma área de estudo que sustenta a si própria”. Principalmente no que tange as iniciativas de divulgação das Ciências, tanto em ambientes formais (escolas e institutos de educação), quanto não formais, como museus, exposições cientificas, programas de TV, web dentre outros, o designer é um mediador de conhecimento, agente ativo na produção de meios visuais, sonoros e táteis que traduzem conceitos abstratos em produtos concretos. Concreto no sentido da apreensibilidade do conteúdo comunicacional que deve estar organicamente inserida no complexo formal e material do projeto de Design, o que conduzirá a uma efetiva experiência estética, compartilhada e inteligível, sendo que essa experiência é igualmente um ato político, sensivelmente partilhada (Rancière, 2005). A relação do Design com os processos sociais é claramente visível, sendo que seus produtos extrapolam o sentido pragmático na relação com o usuário/consumidor, no instante em que essa relação passa a ser afetiva, e os produtos se tornam mediadores de conteúdos simbólicos para além de seu valor enquanto produto material (Ribeiro e Valentim, 2014). Como área transdisciplinar, o Design aporta conhecimentos diversos, proporcionando projetos que aglutinam saberes e, consequentemente, ocasionam o surgimento de outros. A partir das ferramentas do Design, observa-se o acesso a áreas do discurso científico, muitas vezes ininteligível. Afirma-se, assim, que o Design é instrumento cognoscitivo, conector afetivo de valores e significados, mostrando-se importante a discussão a respeito dos processos criativos no Design, enquanto processo cognitivo e profundo de pesquisa, no sentido da proposição de estratégias metodológicas que municiem o designer na sua relação com os profissionais das áreas científicas, gerando aproximações e potencializando o campo da pesquisa em Design.

Fazer Design é um processo de constatar problemas, para além de buscar solucionar problemas. Sem a pretensão de ser um demiurgo, o designer se caracteriza como um solucionador, um buscador de novos desafios, amalgamando práticas e conectando conhecimentos, sendo sua área de atuação uma área de mediação, convergindo abstração e concretude, conforme ensina Costa Jr. (2017). Entretanto, suas práticas não devem ser atreladas ao empirismo, prescindindo de método, organização e processos, fazendo o valor do conhecimento científico se aproximar cada vez mais de suas práticas cotidianas. Portanto, não há como falar do fazer do designer sem falar dos processos que caracterizam suas práticas criativas que o habilitam enquanto agente social, envolvido em uma pluralidade de conceitos que o próprio termo Design evoca. De acordo com Nicolau \& Nicolau (2013, p. 12), "as áreas e sinuosidades do design devem ser avaliadas em conjunto, de forma integrada e orgânica”, dessa forma, indo para além de discurso e áreas de atuação específicos. Nesta mesma direção, Wanderley et al argumentam que: 
$\mathrm{Na}$ atualidade, com uma sociedade imersa em problemas de ordem global e complexa, entre eles, da resistência da pobreza e dos agravamentos da exaustão e degradação do meio-ambiente, assim como de questões de produção, consumo, descarte, educação, acesso a bens de consumo, acesso à informação, economia, comunicação, materialidade, bem-estar, cultura, identidade, democracia, cidadania, etc., parece-nos mais do que justificável uma maior preocupação com uma visão ampla e sistêmica sobre as práticas do design. De uma forma direta ou indireta, o Design, como processo ou resultado de uma configuração, tem algum grau de relação com esses problemas respectivamente complexos em si e, que ainda, podem ser compreendidos nas relações entre eles, em que o todo se torna maior que a mera soma de partes (Wanderley et. al, 2017, p. 11).

De acordo com essas afirmativas, é valido argumentar como as práticas e processos criativos do designer impactam nas dinâmicas complexas da sociedade. Tais práticas, na maioria das vezes centradas nos processos indutivos de raciocínio, ganham força a partir das décadas de 80 e 90 (Bürdeck, 2010), centrando no usuário e suas necessidades, desejos e comportamentos, como a proposta metodológica Design Centrado no Usuário, que se fundamentam em técnicas como entrevistas, observação de campo, prototipagem e testes com e para os usuários (Wanderley et. al., 2017). O Design é área essencialmente transdisciplinar e, como tal, reflete essa visão de mundo nos procedimentos que o municiam tecnicamente, associando conhecimentos, fazeres e especializações de várias áreas.

O design como disciplina perpassa os diversos processos sociais. Sua característica multidisciplinar possibilita as mais diversas interações com os variados campos do conhecimento, deles se aproveitando e com eles contribuindo ao mesmo tempo.

Na contemporaneidade o design tem configuração diversa, com inúmeras possibilidades de relações e associações. É uma grande rede, um tecido entrelaçado e articulado, repleto de significações resultantes do entrelaçamento e articulação de signos que geram linguagens diferenciadas. Essa grande rede flexível atua na esfera da informação, comunicação e conhecimento, tem como foco central o homem, as dinâmicas e produções culturais que o envolvem (Moura, 2011, p. 89).

Dentro dessa visão globalizante do processo do design na contemporaneidade, pensamos em sua interface com a educação. A constante evolução dos dispositivos tecnológicos e midiáticos revolucionou, não apenas as formas de comunicação, mas também os processos de aprendizagem. Hoje qualquer criança pode navegar na internet e pesquisar o que desejar. No entanto, os padrões do ensino tradicional ainda não foram capazes de estabelecer diretrizes que façam frente à sedução das novas mídias. Como afirma Gadotti (2011):

O aluno quer saber, mas não quer aprender, não quer aprender o que lhe é ensinado e nem como é ensinado. [...] a escola ensina num paradigma e o aluno aprende num outro. O que fazer diante do paradoxo: o aluno quer saber, mas não quer aprender? A escola precisa estar atenta às mudanças profundas que 
o contexto midiático contemporâneo está provocando na cabeça de crianças e jovens (Gadotti, 2011, p. 64-65).

Nesse sentido entendemos que a contribuição do Design nos processos de ensino e aprendizagem pode ser um diferencial, pois em suas especificidades ele dialoga com a sociedade, vai refletir seus comportamentos e será objeto de sua própria transformação. Pensamos aqui no processo de pensamento do Design enquanto disciplina e não nos produtos propriamente ditos, ou nas interfaces tecnológicas que ele estabelece. Pensar Design significa aqui, como aponta Nigel Cross, pensá-lo em termos das potencialidades do design na educação que são:

a. desenvolver as habilidades inatas para solucionar problemas do mundo real;

b. estimular a cognição concreta/icônica;

c. oferecer oportunidades para aprimoramento de uma gama de habilidades em pensamento e comunicação não-verbal (Cross, 2004, p. 20).

Essas potencialidades que se revelam nas especificidades do processo de pensamento do Design, vão ao encontro das premissas da dupla ruptura epistemológica apresentada por Boaventura Santos (2003) que se caracteriza pela tensão entre a linguagem técnica e a linguagem metafórica na ciência:

A linguagem técnica desempenha um papel importante na primeira ruptura (que separa a ciência do senso comum), enquanto a linguagem metafórica é imprescindível para a segunda ruptura (que supera tanto a ciência como o senso comum num conhecimento prático esclarecido) (Santos, 2003, pp. 116-117).

Sendo assim, a utilização dos recursos do Design pode promover a construção de caminhos para uma compreensão do conhecimento através de linguagens metafóricas que lhe são próprias, como em seu emprego nas formas de ensino de outras áreas do conhecimento. Um dos principais fatores apontados pelos estudiosos, em relação ao ensino da astronomia, diz respeito ao desconhecimento e à confusão entre as informações que são apreendidas. Langhi (2004) faz um estudo sobre as ideias do senso comum no estudo da Astronomia. Ele destaca a visão de Bisch (1998), que apresenta três traços sobre a natureza das concepções em Astronomia, tanto em estudantes como em professores: o realismo ingênuo, conhecimento conceitual feito de chavões reinterpretados de acordo com o senso comum, e uma representação qualitativa/topológica do espaço. Essas percepções são corroboradas pelos estudos de Leite (2002):

Nos resultados do estudo realizado com uma amostra de dezessete professores de Ciências entre $5^{\circ}$ e $8^{\circ}$ séries da rede pública de ensino de São Paulo, Leite (2002) mostra que a maioria deles concebe a Terra como um objeto plano, bem como o Sol, a Lua e as estrelas. Outros entendem uma Terra esférica, porém com um achatamento exagerado nos pólos. Quanto aos fenômenos astronômicos, tais como dia e noite, estações do ano, eclipses e fases da Lua, 
observou-se excessiva dificuldade na articulação das respostas. Por exemplo, desde uma Lua que não gira até uma Lua com movimento de rotação tal que mostraria todas as suas faces. Ou ainda, suas fases como sendo o resultado da sombra da Terra sobre a Lua. As estações do ano foram confirmadas como sendo provocadas pelo afastamento e aproximação da Terra em relação ao Sol. Muitos indicaram estrelas e Sol como sendo coisas diferentes, enquanto outros nunca ouviram falar sobre buracos negros, até mesmo confundindo-os com o buraco na camada de ozônio (Langhi, 2004, p. 4).

O autor encerra seu artigo refletindo sobre a necessidade de se estabelecerem formas eficazes de se apresentar a astronomia, tanto aos docentes, quanto aos discentes promovendo um conhecimento que fuja das armadilhas dos saberes do senso comum.

\section{Desing dos personagens e paper toys}

Com o objetivo de converter em linguagem visual e objetual alguns dos princípios e conceitos da astronomia para o universo infanto-juvenil, foram desenvolvidos 10 personagens que representam os principais corpos celestes que compõem nosso sistema solar, como mostrado na imagem abaixo (Veja Figura 1).

A cada um desses personagens, foram incorporados aspectos humanos, como personalidade e sentimentos, representando características dos corpos celestes. Um exemplo é o personagem Sol Super Star, que se apresenta como uma celebridade, atraindo a atenção de todos, usando óculos escuros e exibindo um dente de ouro, acessórios comumente vistos em astros do Rap e o Hip Hop.

Os recursos estéticos utilizados têm ligação com o universo dos desenhos animados e revistinhas em quadrinhos japoneses, ou animes e mangas, expressos, por exemplo, por meio das proporções dos olhos dos personagens. Este é mais um recurso que visa aproximar as representações desenvolvidas ao universo popular infantil e juvenil contemporâneo (autores, ano) (Veja Figura 2).

Os personagens foram, então, transformados em paper toys, brinquedos planificados produzidos em papel para montagem, com o propósito de aproximá-los das crianças, como mostrado na figura XXX. Essa forma de corporificação foi eleita para promover um envolvimento maior por parte do público e facilitar a produção e a replicação através de downloads dos arquivos em plataforma online (Veja Figura 3). 


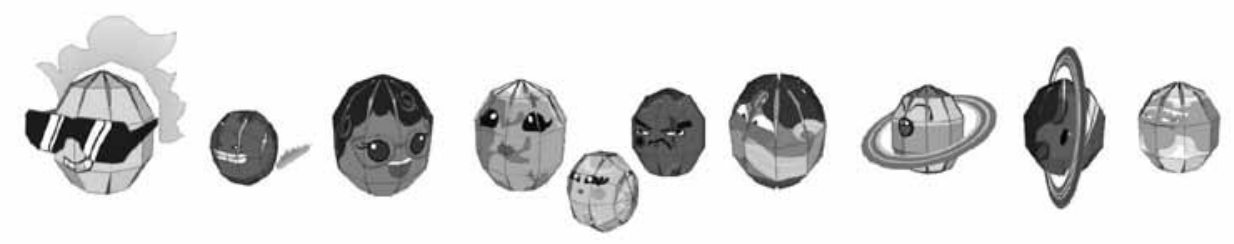

Figura 1.
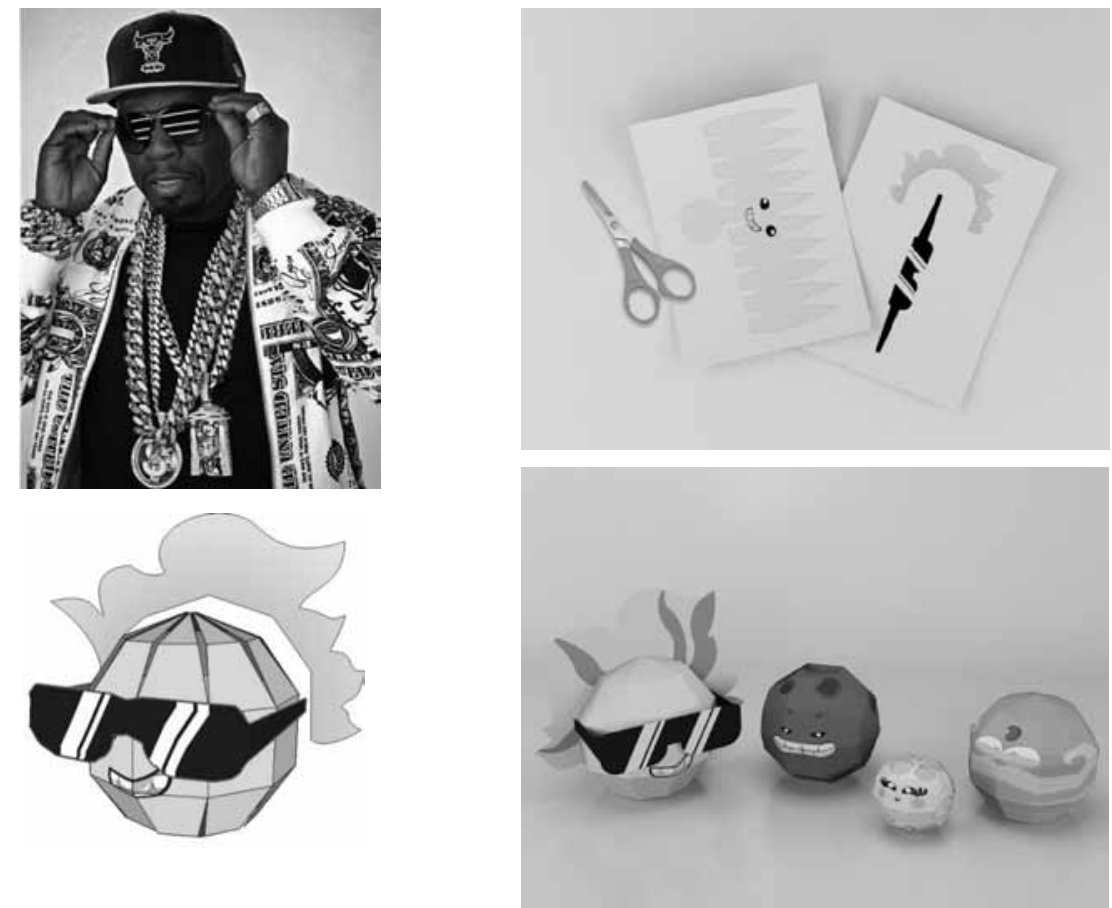

Figura 2.

Figura 3.

Figura 1. Fonte dos autores. Figura 2. Rapper 50 Cent e personagem Sol Super Star (fonte dos autores). Figura 3. Paper toy do personagem Sol Super Star (fonte dos autores) 


\section{Feira INOVAMINAS}

O evento promovido pela FAPEMIG, que ocorreu nos dias 15, 16 e 17 de setembro de 2017 na Praça da Liberdade, foi sede para apresentarmos a pesquisa para a comunidade e observar a interação com os demais, principalmente com o público infantil.

Em nosso estande deixamos à vista os personagens paper toys do Sistema Solar montados, o que bastou para chamar não só a atenção do público infantil, mas também tivemos a atenção dos demais públicos, jovens e adultos.

As crianças interagiram de forma positiva sendo instigadas a tentar acertar qual personagem era, por exemplo, o planeta mercúrio, identificando suas características de cor e forma, textura visual da superfície do planeta, etc.

Muitos adultos que compareceram no local, atuavam como professores de escolas da rede pública e particular, conseguiram visualizar o uso da pesquisa para dar aula de maneira mais lúdica tendo como foco o aprendizado da ciências de forma mais leve e eficaz. Foi relatada também por estes a dificuldade dos alunos em relação ao aprendizado sobre as demais ciências e que o desafio é justamente tornar o assunto interessante e instigador. Muitos apresentaram interesse em expandir parcerias com nosso grupo de pesquisa e inovar na maneira de lecionar.

No final da visita no nosso estande dávamos o envelope com os personagens planificados para recortar e colar para o público ter a experiência de montagem dos personagens criados. Como o evento durou três dias algumas pessoas retornavam ao nosso estande nos dando feedbacks sobre o uso dos personagens com os filhos, a interação deles com a família e amigos.

A partir da percepção dos visitantes a equipe de desenvolvimento do projeto constatou possibilidades de desdobramentos, e ajustes para o projeto, como a ampliação do formato dos paper toys, assim como ajustes para a otimização do sistema de colagem. Assim, os visitantes também se dispuseram a dar seus e-mails pessoais para acompanharem a evolução do projeto e ajudar na divulgação do mesmo.

\section{Open day lab+aberto}

A divulgação do projeto Animando o Ano da Luz, na feira INOVAMINAS, resultou no convite para participar do "Open day lab+aberto" no dia 09 de outubro de 2017. O evento foi uma iniciativa do Laboratório Aberto do Centro de Tecnologia SENAI FIEMG CIT em celebração à Semana das Crianças (no dia 12 de outubro é comemorado no Brasil o dia das crianças) e tinha como público-alvo crianças e adolescentes.

O Laboratório Aberto é um ambiente de aprendizado criado para receber pessoas com diferentes perfis e habilidades. Oferecendo acesso livre a equipamentos, ele estimula o trabalho colaborativo para desenvolvimento de produtos, processos e negócios. [...] Laboratório Aberto fica em uma região conhecida como "Cidade do Conhecimento", por abrigar diversos institutos, universidades, incubadoras e entidades de fomento à pesquisa. 
O evento foi gratuito e divulgado em redes sociais. A proposta era ministrar oficinas que estimulassem o conhecimento e favorecessem o aprendizado. O projeto Animando o Ano da Luz, funcionou como uma oficina de montagem dos paper toys, sob a supervisão de dois pesquisadores do grupo.

Durante a oficina observamos como a montagem dos papers toys possibilitou a interação entre as crianças e adolescentes, estimulou a curiosidade e despertou o interesse pelo tema, astronomia. Verificamos também a observação do público do estilo mangá, em comentários como por exemplo: “a lua é tão kawaii” (criança de dez anos), expressão japonesa que utilizada para ser referir a algo fofo, demonstrando a assimilação dos valores propostos nas definições do projeto de design dos personagens. Notamos também a necessidade de adaptação de alguns dos paper toys, para favorecer a montagem por crianças menores de cinco anos.

\section{Conclusões}

As interações entre o Design e as outras áreas do conhecimento podem surtir efeitos que, infelizmente, são pouco conhecidos e explorados, principalmente quanto à sua interação com os processos de ensino-aprendizagem, que acabam se reduzindo ao âmbito do design instrucional. Por sua natureza híbrida, o design transita com facilidade desde os aspectos práticos até o lado lúdico dos produtos. Ludicidade é uma necessidade quando se trata de ensino para crianças.

Despertar a curiosidade científica é tarefa difícil se usados os métodos tradicionais de ensino, principalmente quando hoje temos as mídias digitais que promovem uma revolução na percepção das crianças desde a mais tenra idade. No entanto, essas mesmas mídias acabam por fazer das crianças mais consumidores de experiências, do que aqueles que promovem as experiências.

A proposta implícita em nosso projeto é resgatar o contato das crianças com o brincar, manuseando materiais, exercitando a coordenação motora ao recortar e montar os paper toys. Promover a interação com os pais na sua montagem e na criação das histórias que envolvem os personagens. Exercitar a criatividade e, ao mesmo tempo, apresentar o fascinante mundo da Astronomia. Muitos de nós tivemos a oportunidade de ouvir histórias sobre os planetas quando crianças. Essas histórias fazem parte hoje de nosso conhecimento e interesse científico.

Ao aliarmos o Design à divulgação científica consideramos criar ferramentas poderosas de transformação social. O ensino, principalmente nos países do Terceiro Mundo, sofre com falta de verbas, falta de qualificação dos docentes e de incentivo. Quando temos a oportunidade de promover a criação de produtos que são acessíveis e podem ser utilizados por qualquer docente sem custo, estamos acreditando num futuro melhor para essas crianças. Que pode estar além das estrelas.

Esse projeto é financiado pela Fundação de Amparo à Pesquisa do Estado de Minas Gerais - FAPEMIG. 


\section{Bibliografia}

Bourdieu, P. (2004). Os usos sociais da ciência: por uma sociologia clínica do campo científico. São Paulo: UNESP.

Bisch, S. (1998). Astronomia no ensino fundamental: natureza e conteúdo do conhecimento de estudantes e professores. São Paulo: Universidade de São Paulo. Tese de Doutorado.

Bomfim, G. (1999). “Algumas considerações sobre teoria e pedagogia do design”, em Estudos em Design, $\mathrm{n}^{\circ 2}$, vol.7, Rio de Janeiro: 2AB, pp. 22-39.

Bulgarelli, D. e Haun, L. (2007). “Brincando e aprendendo astronomía”, em X Reunión de la Red de Popularización de la Ciencia y la Tecnología en América Latina y el Caribe (RED POP - UNESCO) e IV Taller "Ciencia, Comunicación y Sociedad”, Costa Rica.

Bürdek, B. (2010). História, teoria e prática do design de produtos. São Paulo: Blücher.

Campos, A. (2016). "Inventório: Processos de divulgação científica para crianças: estudo de caso de livro informativo", Dissertação de Mestrado, Faculdade de Arquitetura e Urbanismo da Universidade de São Paulo, 2016.

Correia, R. (2003). "A Interacção do Design Industrial com a Ciência e a Tecnologia: a abordagem interdisciplinar", Dissertação para obtenção de título de mestre em desenho industrial, Escola Superior de Artes e Design de Matosinhos, Faculdade de Engenharia da Universidade do Porto, Portugal.

Costa, Jr. (2017). "O design com estratégia de divulgação científica: o caso da FAPEMIG", em Fagundes, V. e Silva, M. (2017). Divulgação Científica: novos horizontes - reflexões e experiências jornalístico-acadêmicas desenvolvidas no projeto Minas Faz Ciência. Belo Horizonte: Mazza, p. 180.

Cross, N. (2004). Desenhante: pensador do desenho. Santa Maria: sCHDs.

Emar de Almeudia, D. (2012). "Multiverso: reconstrução de modelo análogo ao espaço sideral para divulgação da ciência”, em Dissertação de Mestrado apresentada ao Programa de Pós-graduação em Educação tecnológica, Centro Federal de Educação Tecnológica de Minas Gerais CEFET-MG, Belo Horizonte.

Gadotti, M. (2011). Boniteza de um sonho: ensinar e aprender com sentido. São Paulo: Ed. L.

Kosminsky, D. (2015). "Visualização de informação para divulgação científica: uma metodologia”, em Spinillo, C. et.al. (2015). Anais do $7^{\circ}$ Congresso Internacional de Design da Informação/Proceedings of the 7th Information Design International Conference, Blucher Design Proceedings, no 2, vol.2, ISSN 2318-6968, São Paulo: Blucher.

Langhi, R. (2004). "Ideias de Senso Comum em Astronomia", em 7o Encontro Nacional de Astronomia (ENAST).

Langhi, R. e Nardi, R. (2005). "Dificuldades interpretadas nos discursos de professores dos anos iniciais do ensino fundamental em relação ao ensino da astronomia”, em Revista Latino-Americana de Educação em Astronomia - RELEA, no 2, p. 75-92.

Löbach, B. (2001). Design Industrial. Bases para a configuração dos produtos industriais. São Paulo: Edgard Blücher, 2001.

Lima, E. e Martins, B. (2011). "Design social, o herói de mil faces, como condição para atuação contemporânea”, em Braga, M. (2011). O Papel Social do Design Gráfico. São Paulo: SENAC-SP. 
McCraken, G. (2007). "Cultura e Consumo: uma Explicação Teórica da Estrutura e do Movimento do Significado Cultural dos Bens de Consumo”, em São Paulo: RAE-Revista de Administração de Empresas, vol. 47, n 1, jan-mar 2007.

Morin, E. (2005). Ciência com consciência. Rio de Janeiro: Bertrand.

Moura, M. (2011). "Ensino e design no contemporâneo: dúvidas, desafios, expressões e discursos", em Ensaios em Design: ensino e produção de conhecimento, Bauru, Canal 6, 2011, pp. 82-113.

Oliveira, A. (2010). "Construção e aplicação de modelos analógicos no ensino de ciências: o planetário líquido”, Dissertação de Mestrado, Programa de Pós-graduação em Educação tecnológica, Centro Federal de Educação Tecnológica de Minas Gerais, Belo Horizonte, 2010.

Nagem, R. et.al. (2010). "Gênese, construção e aplicação de modelo analógico para o ensino de conceitos sobre astronomia”, em II SENEPT - Seminário Nacional de Educação Profissional e Tecnológica.

Rancière, J. (2005). A partilha do Sensivel: estética e política. São Paulo: EXO experimental. Nicolau, R. e Nicolau, V. (2013). "Design, teoria e prática”, em Nicolau, R. (2013). Zoom: design, teoria e prática. João Pessoa: Ideia.

Redig, J. (2011). “Design: responsabilidade social no horário do expediente”, em Braga, M. (2011). O Papel Social do Design Gráfico. São Paulo: SENAC-SP.

Ribeiro, R. e Valetim, C. (2014). Design \& arte: entre os limites e as interseções. Contagem: Ed. do Autor.

Santos, B. (2003). Introdução a uma ciência pós-moderna. Rio de Janeiro: Graal.

Wanderley, M. et.al. (2017). "Bases Comuns do Design: uma discussão sobre o impacto e papel social do design”, em Arruda, A. (2017). Design \& Complexidade. São Paulo: Blucher.

Resumen: El artículo presenta la experiencia de utilización de herramientas del Diseño para la divulgación científica infantil, a partir del proyecto "Animando el año de la luz: el diseño presenta la astronomía para niños", desarrollado por el Grupo de Investigación en Diseño y Representaciones Sociales de la Universidad del Estado de Minas Gerais y financiado por la Fundação de Amparo à Pesquisa do Estado de Minas Gerais (FAPEMIG). La propuesta es asociar el conocimiento específico astronómico a los procesos de construcción simbólica del Diseño, adaptando los lenguajes y comunicaciones para permitir presentar el universo de conocimiento de la ciencia de forma lúdica. La metodología utilizada busco brindar una interfaz entre los procesos de enseñanza y de aprendizaje y el carácter lúdico de los recursos creados por el diseño. Los procesos metodológicos incluyen relevamiento de material bibliográfico, estudio de las necesidades comunicacionales y diseño del material a utilizarse. El artículo aborda la primera fase del proyecto, contemplando el diseño, divulgación y distribución del kit de paper toys con personajes que representan los elementos del sistema solar en dos eventos realizados en el año 2017, en la ciudad de Belo Horizonte, Brasil.

Palabras clave: diseño - divulgación científica - enseñanza - astronomía. 


\begin{abstract}
The article presents the perspective of the use of the tools of the Design for the scientific divulgation for children from the project "Animating the Year of the light: the design presents the astronomy for children", developed by the Grupo de Pesquisa Design e Representações Sociais da Universidade do Estado de Minas Gerais and financed by the Fundação de Amparo à Pesquisa do Estado de Minas Gerais (FAPEMIG). His proposal is to combine the specific knowledge about Astronomy to the processes of symbolic construction of Design adapting them to the languages and communications that allow to present a universe of the knowledge of science in a playful way.

The methodology used sought to promote the interface between the teaching and learning processes, with the playful nature of the devices created by the design. The methodological processes include a bibliographical reference survey, a study of communication needs and the design of the material. This paper will cover the first phase of the project, including the design, dissemination and distribution of the paper toys kit with characters that represent the Solar System in two events in 2017, in the city of Belo Horizonte, Brazil.
\end{abstract}

Keywords: design - scientific dissemination - teaching - astronomy. 